Open Access

\title{
ER, PgR, Ki67, p27 Kip1 and histological grade as predictors of pathological complete response in patients with HER2- positive breast cancer receiving neoadjuvant chemotherapy using taxanes followed by fluorouracil, epirubicin, and cyclophosphamide concomitant with trastuzumab
}

Sasagu Kurozumi ${ }^{1}$, Kenichi Inoue ${ }^{2}$, Hiroyuki Takei ${ }^{1}$, Hiroshi Matsumoto ${ }^{1}$, Masafumi Kurosumi ${ }^{3^{*}}$, Jun Horiguchi ${ }^{4}$, Izumi Takeyoshi $i^{4}$ and Tetsunari Oyama ${ }^{5}$

\begin{abstract}
Background: Neoadjuvant chemotherapy (NAC) with taxanes followed by fluorouracil, epirubicin, and cyclophosphamide (FEC), and concurrent trastuzumab is a potent regimen for HER2 over-expressing breast cancer. A high pathological complete response $(p C R)$ rate has been achieved using this regimen; however, the predictive factors and prognostic effects of $\mathrm{pCR}$ currently remain unclear. In the present study, we determined whether $\mathrm{pCR}$ was related to histological grade $(\mathrm{HG})$ and several biological factors including $\mathrm{p} 27^{\mathrm{Kip} 1}$. We also assessed the prognosis of the pCR and non-pCR groups, and expected differences between those positive and negative for lymph node metastasis after chemotherapy.
\end{abstract}

Methods: A total of 129 Japanese women with HER2-positive invasive breast cancer received either paclitaxel or docetaxel followed by FEC, with the concomitant administration of trastuzumab. The statuses of HG, ER, PgR, Ki67, and p2 $7^{\text {Kip } 1}$ were evaluated to determine their relationship with pCR. Relapse-free survival (RFS) and overall survival (OS) were also analyzed for their relationship with pCR and pathological nodal involvement.

Results: pCR was obtained in 84 out of 129 patients and the pCR rate was $65.1 \%$. The $p C R$ rates related to 5 factors were as follows: HG (grade 3, $70.0 \%$ vs. grades 1-2, $36.8 \%$ ), ER (negative, $78.6 \%$ vs. positive, $40.0 \%$ ), PgR (negative, $75.3 \%$ vs. positive, $38.9 \%$ ), Ki67 (high, $72.0 \%$ vs. low, $47.2 \%$ ), and p27 Kip1 (low, $71.0 \%$ vs. high, $50.0 \%$ ). RFS was significantly better in the $p C R$ group than in the non-pCR group $(p=0.018)$. Patients with remaining nodal disease in the $\mathrm{pCR}$ group had worse OS ( $p=0.0002)$.

Conclusions: High-HG, low-ER, low-PgR, high-Ki67, and low-p27 $7^{\text {Kip } 1}$ were identified as predictive factors of pCR in NAC with trastuzumab, while $P C R$ and negative nodes were predictive of better survivals.

\footnotetext{
*Correspondence: mkurosumi@cancer-c.pref.saitama.jp

${ }^{3}$ Department of Pathology, Saitama Cancer Center, 780 Komuro, Ina-machi,

Kitaadachi-gun, Saitama 362-0806, Japan

Full list of author information is available at the end of the article
} 


\section{Background}

Many neoadjuvant chemotherapy (NAC) regimens for breast cancer that use various cytotoxic agents are currently being performed in clinical studies as well as routine practice, and NAC is considered a useful therapeutic option for advanced as well as early stage breast cancer patients. NAC improves surgical outcomes in advanced cases for which mastectomy is technically impossible and in early cases of operable breast cancer desiring breast conservative surgery. The therapeutic effects of NAC have mainly been evaluated on the basis of the pathological findings and results of most clinical studies including NSABP protocol B-18 [1] and B-27 [2]. These studies confirmed the prognostic significance of pathological complete response (pCR). On the basis of these findings, pCR has been positioned as a primary endpoint of NAC in many clinical studies and clinical trials of new chemotherapeutic agents.

Approximately 20 to $30 \%$ of breast cancers over express human epidermal growth factor receptor 2 (HER2) [3], and effective HER2-targeting agents such as trastuzumab have recently been added to NAC regimens [4-6]. However, the pCR rate of NAC using taxanes and trastuzumab has remained between 20 and $40 \%$ [4, 7]. An anthracycline has also been added to NAC regimens with trastuzumab in an attempt to obtain a higher $\mathrm{PCR}$ rate. Buzdar et al. [8] conducted a NAC regimen with tri-weekly paclitaxel followed by fluorouracil, epirubicin, and cyclophosphamide (FEC) concurrently with trastuzumab on HER2-positive patients and achieved a PCR rate of $66.7 \%$ without serious adverse events. However, the predictive factors of $\mathrm{pCR}$ in patients with HER2-positive breast cancer receiving trastuzumab supplemented NAC regimens have not been clarified.

In the present study, we analyzed several factors, such as the histological grade (HG), ER status, PgR status, Ki67 (proliferation marker) labeling index (LI), and expression of $\mathrm{p} 27^{\mathrm{Kip} 1}$ (an anti-proliferation marker) in order to identify more effective predictive markers for pCR after NAC with trastuzumab. We also assessed differences in survival between the pCR and non-pCR groups, and between patients who tested positive and negative for lymph node metastasis.

\section{Methods}

\section{Patient backgrounds and eligibility}

Our study included 129 female patients with HER2-positive invasive breast cancer. They received NAC consisting of 12 cycles of paclitaxel $\left(80 \mathrm{mg} / \mathrm{m}^{2}\right)$ every week or 4 cycles of docetaxel $\left(75 \mathrm{mg} / \mathrm{m}^{2}\right)$ every 3 weeks followed by 4 cycles of FEC-75 (5-fluorouracil, $500 \mathrm{mg} / \mathrm{m}^{2}$, epirubicin, $75 \mathrm{mg}$ / $\mathrm{m}^{2}$; and cyclophosphamide, $500 \mathrm{mg} / \mathrm{m}^{2}$ ) every 3 weeks. All patients also received $4 \mathrm{mg} / \mathrm{kg}$ trastuzumab on day 1 of the treatment and $2 \mathrm{mg} / \mathrm{kg}$ trastuzumab every week thereafter for a total of 24 cycles. NAC with trastuzumab for these patients was performed to evaluate the impact of pathological therapeutic effects evoked by additional administration of trastuzumab, and the main aims of this therapy for each patient were reduction of tumor size for prior to breast-conserving surgery, and evaluation of drug effect through pathological assessment of tumor response and good prognosis in cases achieving $\mathrm{pCR}$.

The main eligibility criteria were: age $\geq 20$ years, an Eastern Cooperative Oncology Group performance status of $0-1$, adequate oral intake, preserved major organ functions, and the ability to provide informed consent. Patients were excluded if they had a previous history of therapy for breast cancer, inflammatory breast cancer, a history of severe anaphylaxis or allergies to any drug, significant active illness that may preclude the protocol treatment, a history of uncompensated congestive heart failure, or severe mental disease. Pregnant or lactating females were also excluded. This protocol is now accepted as standard care. Approximately $97 \%$ of patients completed this regimen of treatment. However, some patients receiving the same regimen of treatment were excluded from this study because their paraffin-embedded pre-treatment biopsy specimens could not be obtained. In approximately $40 \%$ of patients, sentinel lymph node biopsy was performed using a combination method with an isotope (99mTc-sulfur colloid) and blue dye.

We extracted information from the institutional clinical and pathological database on all consecutive breast cancer patients who underwent surgery between 2005 and 2011 at the Division of Breast Surgery in the Saitama Cancer Center. All patients received an adjuvant trastuzumab treatment for six months, and adjuvant endocrine therapy using tamoxifen or an aromatase inhibitor was performed on ER-positive patients. This study was conducted in accordance with the Declaration of Helsinki, and the protocol of NAC used in this study and associated translational researches were approved by the Institutional Review Board of the Saitama Cancer Center. All patients enrolled in this study agreed to be treated with this NAC regimen and provided written informed consent.

\section{Evaluation of histological effects}

Pathological effects after NAC were evaluated by 2 pathologists according to the criteria proposed by the Japanese Breast Cancer Society (JBCS). In these criteria, pathological effects were categorized into $6^{\circ}$, such as grade $0,1 \mathrm{a}, 1 \mathrm{~b}, 2 \mathrm{a}, 2 \mathrm{~b}$, and 3 , on the basis of morphological changes and the extent or absence of invasive cancer. Grade 1a was defined as "mild changes in cancer cells regardless of the extent, and/or marked changes in $<1 / 3$ of the tumor". Grade 1b was defined as "marked changes in $1 / 3$ to $<2 / 3$ of the tumor". Grade 2 a was defined as "marked changes in $\geq 2 / 3$ of the tumor, but apparent 
remaining cancer cells". Grade 2b was defined as "marked changes approaching a complete response with only a few remaining cancer cells". The JBCS defines "grade 3" as "no invasive cancer in the breast", which is equal to "pCR" proposed in the NSABP B-18 study. The presence of non-invasive cancers (DCIS) in the breast and nodal involvement in such cases was clearly stated. This response was designated as ypT0/is ypNo/1-3 according to the TNM staging criteria of the AJCC (American Joint Committee on Cancer Staging System).

\section{Examination of biological markers in relation to $\mathrm{PCR}$ rates} The expression of ER, PgR, and HER2 proteins was examined by immunohistochemistry and HER2 gene amplification was evaluated by fluorescence in situ hybridization (FISH) using specimens obtained by needle biopsy as a routine practice before NAC. On the other hand, the expression of Ki67 and p27 ${ }^{\mathrm{Kip} 1}$ was retrospectively examined by immunohistochemistry using needle biopsy specimens as part of this study. Primary antibody sources were as follows: ER (1D5, DAKO, Denmark), PgR (PgR636, DAKO, Denmark), HER2 (HercepTest, DAKO, Denmark), Ki67 (MIB-1, DAKO, Denmark), and p27 ${ }^{\text {Kip1 }}$ (Santa Cruz Biotechnology, USA). Positive ER and PgR statuses were defined by the presence of $1 \%$ or more positive nuclei. A high Ki-67 LI and strong expression of p27 ${ }^{\text {Kip1 }}$ were defined by the presence of $30 \%$ and $75 \%$ or more positive nuclei, respectively (Fig. 1a). Cancer cells that positively expressed p $27^{\mathrm{Kip} 1}$ in the cytoplasm were categorized as "negative" (Fig. 1b). The ER status (positive vs. negative), PgR status (positive vs. negative), Ki67 LI (high vs. low), and p27 $7^{\text {Kip } 1}$ expression (high vs. low) at baseline were analyzed for their relationships with $\mathrm{pCR}$.

\section{Clinical outcome analysis}

Clinical and tumor characteristics at baseline such as age, menopausal status, clinical tumor size, clinical nodal status, and HG (grades 1-2 vs. grade 3 ) were analyzed for their relationship with $\mathrm{PCR}$ and with the presence of pathological axillary lymph node metastasis. Recurrencefree survival (RFS) and overall survival (OS) were compared according to the achievement of $\mathrm{pCR}$ and pathological nodal involvement.

\section{Statistical analysis}

Statistical analyses were conducted using Stat Mate 4 for Windows (ATMS, Tokyo, Japan). The Chi-squared test and Fisher's exact test were used to analyze relationships between clinicopathological characteristics and pCR. In addition, a multivariate analysis of logistic regression was used to determine which factors were independently associated with $\mathrm{pCR}$.

The Kaplan-Meier method and log-rank test were used to estimate RFS and OS rates. RFS was defined as the length of time from the period of surgery to any recurrence (including ipsilateral breast recurrence). OS was determined as the time from the day of surgery until the time of death (from any cause). The log-rank test was used to compare survival rates between patients with $\mathrm{pCR}$ and those with non-pCR. Survival rates were analyzed for their relationship with pathological nodal involvement in the pCR group.

\section{Results}

\section{Patient and tumor characteristics}

The median age of the 129 patients enrolled in this study was 53 years (age range, 27-73 years); 109 patients $(84.5 \%)$ were older than 41 years and 78 patients $(60.5 \%)$ were post-menopausal. Tumor sizes (AJCC) were as follows: T1, 6 patients (4.7 \%); T2, 81 patients (62.8\%); T3, 26 patients (20.2 \%); and T4, 16 patients (12.4\%). The clinical lymph node status was as follows: N0, 41 patients (31.8\%); N1, 59 patients (45.7\%); N2, 17 patients (13.2\%); and N3, 12 patients (9.3\%). Breast cancer stages were as follows: stage I, 2 patients (1.6\%); stage IIA, 37 patients $(28.7 \%)$; stage IIB, 38 patients $(29.5 \%)$; stage IIIA, 29 patients (22.5\%); stage IIIB, 11 patients ( $8.5 \%)$; and stage IIIC, 12 patients (9.3\%). In $38.8 \%$ of all cases,

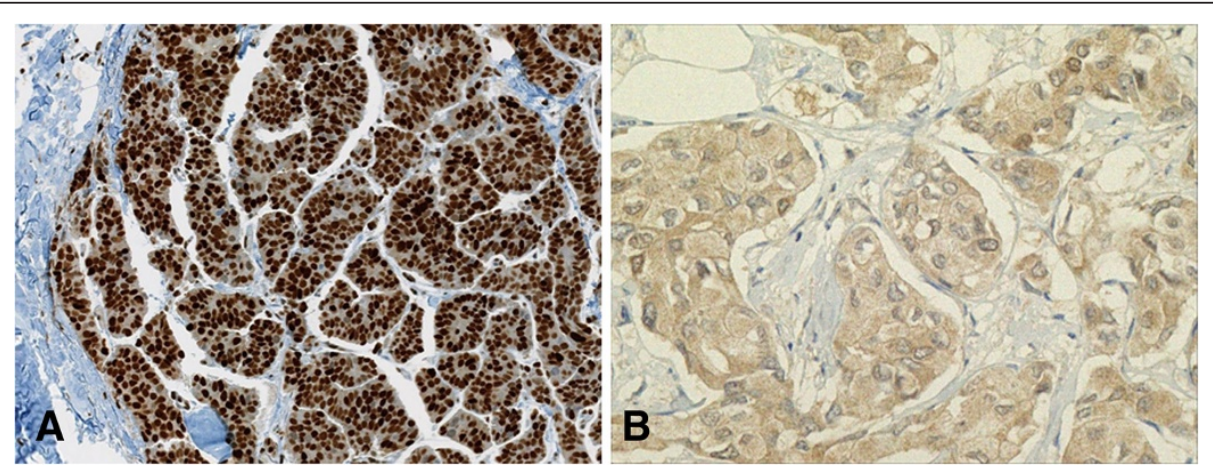

Fig. 1 Immunohistochemical findings of p27. $7^{\text {Kip } 1}$ a Nuclei of cancer cells showing highly positive immunoreactions for p2 $7^{\text {Kip } 1}$. b The cytoplasm of cancer cells was weakly positive, whereas the nuclei were negative for $p 27^{\text {Kip } 1}$ 
lymph node dissection was avoided, because of negative for metastasis in sentinel lymph nodes (Additional file 1); the median number of nodes removed by axillary lymph node dissection was 11 (range, 2-23), and he median number of nodes sampled only by sentinel lymph node biopsy was 2 (range, 1-5).

\section{Tumor response}

Eighty-four (65.1\%) out of the 129 patients achieved pCR (grade 3, JBCS criteria). Of these, 5 patients (3.9\%) had lymph node metastasis (ypN1-3) and 31 (24.0\%) had DCIS. The histological tumor responses of the 45 patients who did not achieve pCR (non-pCR) were as follows: grade $2 \mathrm{~b}$ (near-pCR), 11 patients $(8.5 \%)$; grade $2 \mathrm{a}, 17$ patients $(13.2 \%)$; grade $1 \mathrm{~b}, 12$ patients $(9.3 \%)$; and grade $1 \mathrm{a}, 5$ patients $(3.9 \%)$. A prominent tumor response (pCR and near-pCR) was detected in $73.6 \%$ of patients.

\section{Patient and tumor characteristics and biological markers associated with $\mathrm{pCR}$}

pCR rates were not associated with clinical T $(p=0.62)$, clinical N $(p=0.96)$, or clinical stages $(p=0.97)$; however, $\mathrm{pCR}$ rates correlated with the menopausal status $(p=$ 0.019 ) (Table 1 ). pCR rates were also significantly higher in patients with HG $3(p=0.005)$, ER-negative $(p<0.001)$, and PgR-negative $(p<0.001)$ tumors than in those with HG 1-2, ER-positive, and PgR-positive tumors, respectively (Table 1 ). pCR rates were also significantly higher in patients whose tumors had a high Ki67 LI $(p=0.008)$ or weakly expressed $\mathrm{p} 27^{\mathrm{Kip} 1}(p=0.025)$ (Table 1$)$. The multivariate analysis indicated that none of the factors were significant (Additional file 2). Therefore, the relationship between pCR rates and the 5 biological markers (HG, ER, PgR, Ki67, and p27 ${ }^{\text {Kip1 }}$ ) combined was evaluated. One point each was assigned for high HG, ER negative, PgR negative, high Ki-67 LI, and low p27 ${ }^{\mathrm{Kip} 1}$ expression. pCR rates among patients with $5,4,3,2,1$, and 0 points were $84.3 \%, 74.1 \%, 47.8 \%, 47.1 \%, 28.6 \%$, and none, respectively. This $\mathrm{pCR}$-predicting score significantly predicted pCR $(p=0.0001)$ (Table 2 and Additional file 3$)$.

\section{Survival}

The median RFS was 53 months (range, 3-108 months) and median follow-up duration was 59 months (range, 13-108 months). RFS was significantly better in the 84 patients with $\mathrm{pCR}$ after NAC with trastuzumab than in the 45 patients with non-pCR [hazard ratio $(\mathrm{HR})=0.40$, $95 \% \mathrm{CI}=0.15$ to $0.79, p=0.012$ ] (Fig. 2). Of the 84 patients with $\mathrm{pCR}$, OS was significantly worse in those with pathologically involved nodes (ypT0/is ypN1-3) (5 patients) than in those without pathologically involved nodes (ypT0/is ypN0) (79 patients) ( $\mathrm{HR}=0.075,95$ $\% \mathrm{CI}=0.019$ to $0.29, p=0.0002$ ) (Fig. 3). Among patients
Table 1 Patient and tumor characteristics at baseline and their relationship with $\mathrm{pCR}$

\begin{tabular}{|c|c|c|c|c|}
\hline & $\mathrm{pCR}$ & non-pCR & $\mathrm{pCR}$ rate $(\%)$ & $p$-value \\
\hline \multicolumn{5}{|l|}{ Menopausal status } \\
\hline Premenopausal & 27 & 24 & 52.9 & \\
\hline Postmenopausal & 57 & 21 & 73.1 & $0.019^{*}$ \\
\hline \multicolumn{5}{|l|}{ Clinical tumor size } \\
\hline $\mathrm{T} 1$ & 4 & 2 & 66.7 & \\
\hline $\mathrm{T} 2$ & 56 & 25 & 9.1 & \\
\hline T3 & 15 & 11 & 57.7 & \\
\hline T4 & 9 & 7 & 56.2 & 0.62 \\
\hline \multicolumn{5}{|l|}{ Clinical nodal status } \\
\hline NO & 27 & 14 & 65.9 & \\
\hline N1 & 39 & 20 & 66.1 & \\
\hline $\mathrm{N} 2$ & 11 & 6 & 64.7 & \\
\hline N3 & 7 & 5 & 58.3 & 0.96 \\
\hline \multicolumn{5}{|l|}{ Clinical stage } \\
\hline I & 1 & 1 & 50.0 & \\
\hline$\| A$ & 26 & 11 & 70.3 & \\
\hline$\| B$ & 24 & 14 & 63.2 & \\
\hline$\| \mathrm{A}$ & 19 & 10 & 65.5 & \\
\hline$\| \mathrm{IIB}$ & 7 & 4 & 63.6 & \\
\hline IIIC & 7 & 5 & 58.3 & 0.97 \\
\hline \multicolumn{5}{|l|}{ Type of Taxanes } \\
\hline Paclitaxel & 78 & 39 & 66.7 & \\
\hline Docetaxe & 6 & 6 & 50.0 & 0.40 \\
\hline \multicolumn{5}{|l|}{$H G$} \\
\hline High (3) & 77 & 33 & 70.0 & \\
\hline Low (1-2) & 7 & 12 & 41.2 & $0.005^{*}$ \\
\hline \multicolumn{5}{|l|}{ ER } \\
\hline Negative (<1 \%) & 66 & 18 & 78.6 & \\
\hline Positive ( $\geq 1 \%$ ) & 18 & 27 & 40.0 & $<0.001 *$ \\
\hline \multicolumn{5}{|l|}{$\mathrm{PgR}$} \\
\hline Negative (<1 \%) & 70 & 23 & 75.3 & \\
\hline Positive ( $\geq 1 \%$ ) & 14 & 22 & 38.9 & $<0.001 *$ \\
\hline \multicolumn{5}{|l|}{ Ki67 } \\
\hline High ( $\geq 30 \%$ ) & 67 & 26 & 72.0 & \\
\hline Low (<30 \%) & 17 & 19 & 47.2 & $0.008^{*}$ \\
\hline \multicolumn{5}{|l|}{$\mathrm{p} 27^{\mathrm{Kip} 1}$} \\
\hline Low (<75 \%) & 66 & 27 & 71.0 & \\
\hline High ( $\geq 75 \%)$ & 18 & 18 & 50.0 & $0.025^{*}$ \\
\hline
\end{tabular}

$p C R$, pathological complete response; $H G$, histological grade; $E R$, estrogen receptor; $P g R$, progesterone receptor

${ }^{*} p<0.05$ was considered significant; all significant values are shown in bold

with ER-positive tumors, $\mathrm{pCR}$ was significantly predictive of better RFS if the tumors had a high Ki67 LI ( $p=0.004)$; however, $\mathrm{pCR}$ was not predictive of RFS rates if tumors 
Table 2 pCR prediction scores and their relationship with pCR

\begin{tabular}{|c|c|c|c|c|}
\hline Scores & $\mathrm{pCR}$ & Non-pCR & pCR rate $(\%)$ & $p$-value \\
\hline$\overline{0}$ & 0 & 4 & - & \\
\hline 1 & 2 & 5 & 28.6 & \\
\hline 2 & 8 & 9 & 47.1 & \\
\hline 3 & 11 & 12 & 47.8 & \\
\hline 4 & 20 & 7 & 74.1 & \\
\hline 5 & 43 & 8 & 84.3 & $0.0001^{*}$ \\
\hline
\end{tabular}

showed a low Ki67 LI. pCR was significantly predictive of better RFS rates in patients with tumors revealing a high Ki67 LI $(\mathrm{HR}=0.036,95 \% \mathrm{CI}=0.085$ to $0.82, p=0.021)$, but not in patients with tumors showing a low Ki67. pCR was predictive of better RFS in patients with tumors that weakly expressed p27 ${ }^{\mathrm{Kip} 1},(\mathrm{HR}=0.35,95 \% \mathrm{CI}=0.094$ to $0.72, p=0.010$ ), but not in patients with tumors that strongly expressed $\mathrm{p} 27^{\mathrm{Kip} 1}$.

\section{Discussion}

In the present study, we clarified that NAC with taxanes followed by FEC concurrently with trastuzumab was useful for obtaining a high pCR rate of more than $65 \%$ and the statuses of high HG, low ER, low PgR, high Ki67, and low p27 ${ }^{\mathrm{Kip} 1}$ appeared to be predictive factors for a high pCR rate. Furthermore, prognoses were significantly better in patients with pCR and pathologically negative lymph nodes after NAC with trastuzumab.

Trastuzumab, a humanized monoclonal antibody to the HER2 protein, binds to the extracellular domain of HER2, which is localized in the cell membrane of carcinoma cells, and inhibits their proliferation by arresting the cell cycle during the G1 phase $[9,10]$. Trastuzumab

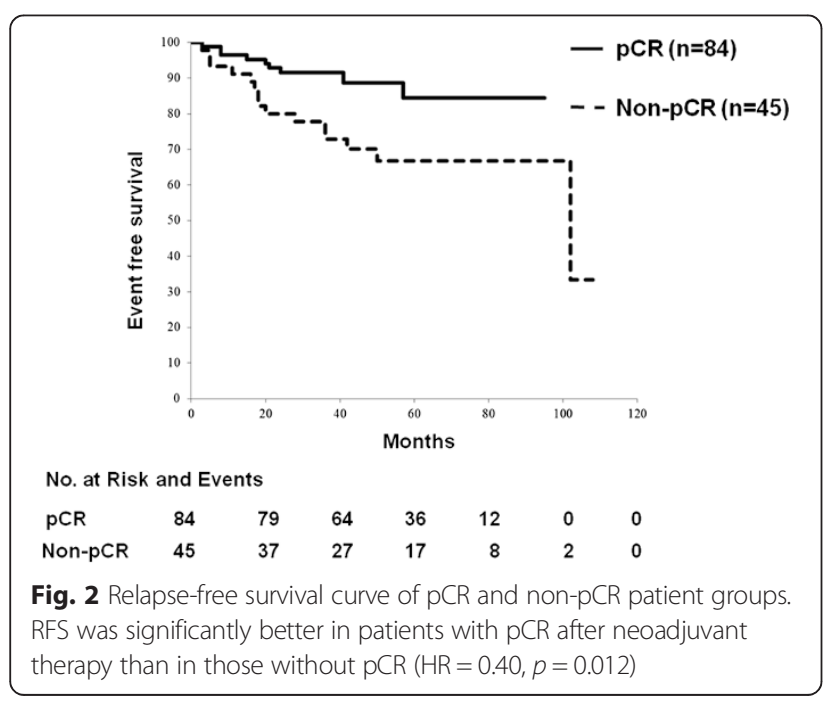

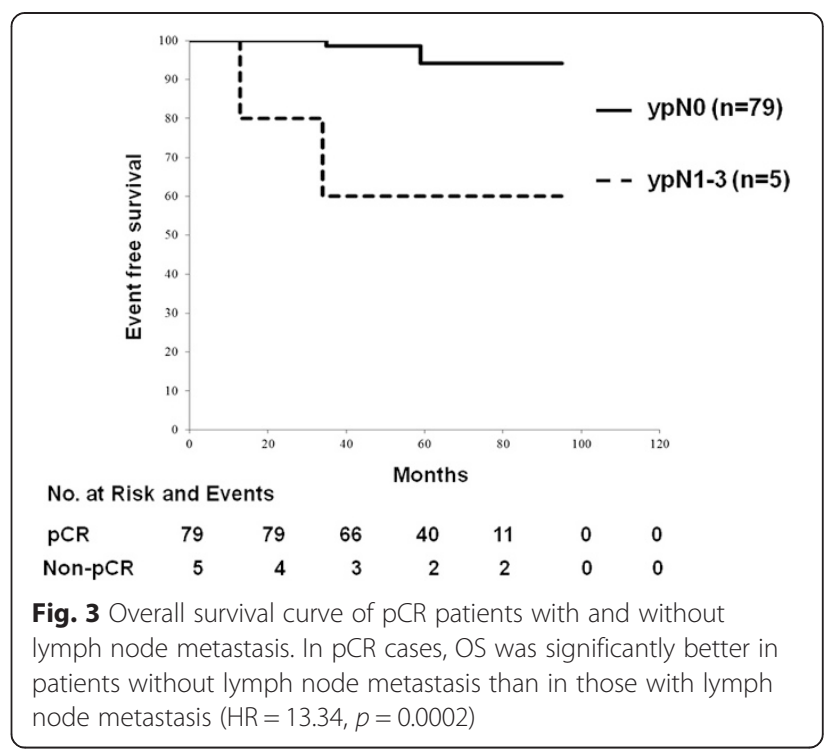

has been suggested to inhibit HER2 action by preventing HER2 dimerization and subsequent signal transduction via the phosphatidylinositol 3-kinase (PI3K) cascade $[11,12]$. It also causes antibody-dependent, cell-mediated cytotoxicity, and its binding to cancer cells triggers their killing by immune cells $[13,14]$. Since trastuzumab was accepted as a new agent for breast cancer patients with HER2 over-expressing tumors by the Food and Drug Administration (FDA) in 1998, the strategy of breast cancer treatment has markedly changed in the last decade.

Preclinical models suggested that the concurrent administration of trastuzumab and chemotherapy was synergistic [15-17], and Siedman et al. [18] reported that chemotherapy using trastuzumab $(2 \mathrm{mg} / \mathrm{kg})$ and paclitaxel $90 \mathrm{mg} / \mathrm{m}^{2}$ was clinically effective for metastatic breast cancer patients with HER2-positive tumors, with overall response rates ranging between 67 and $81 \%$. Trastuzumab has also been used in adjuvant therapy, and Smith et al. [19] reported that a 1-year treatment with trastuzumab after adjuvant chemotherapy in the HERA study led to significant overall survival benefits. When administered concurrently with NAC, trastuzumab was shown to markedly improve $\mathrm{pCR}$ rates in patients with HER2-positive tumors $[4,7]$. Buzdar et al. $[8,20]$ also reported a pCR rate of $66.7 \%$ in NAC with tri-weekly paclitaxel followed by FEC concurrently with trastuzumab. Our modified regimen, such as "weekly paclitaxel instead of tri-weekly or tri-weekly docetaxel", also achieved a pCR rate of $65.1 \%$. However, the pCR rate decreased to $61.2 \%$ when the 5 patients with pathologically involved nodes were excluded. In addition, the foci of DCIS remained in $24.0 \%$ of cases. Therefore, DCIS may be less responsive to this kind of therapy because the carcinoma cells of DCIS are localized in pre-existing lactiferous ducts without feeding vessels. 
Few studies have attempted to identify the predictive markers of pCR after NAC in patients with HER2positive tumors $[21,22]$. In our translational research to obtain higher $\mathrm{pCR}$ rates, we clarified the relationship between $\mathrm{pCR}$ rates and the statuses of several biological factors. The negative expression of hormone receptors (ER and PgR) may be important for predicting pCR in NAC with trastuzumab. The pCR rate of the ER-negative group $(78.6 \%)$ was higher than that of the ER-positive group (40.0\%), and was also higher in the PgR-negative group (75.3 \%) than in the PgR-positive group (38.9\%). Furthermore, an evaluation of the high proliferation marker (Ki67) LI was considered to be useful for estimating pCR, with the pCR of the high Ki67 ( $\geq 30 \%$ ) group $(72.0 \%)$ being higher than that of the low Ki67 group (47.2\%). An estimation of HG may also be useful for the selection of high $\mathrm{pCR}$ patients because the $\mathrm{pCR}$ rate of the high HG (grade 3) group was $70.0 \%$ while that of the low HG group (grade 1-2) was $36.8 \%$.

On the other hand, $\mathrm{p} 27^{\mathrm{Kip} 1}$ is a cyclin dependent kinase inhibitor that normally acts as a tumor suppressor protein [23-26]; however, the relationship between the expression of $\mathrm{p} 27^{\mathrm{Kip} 1}$ and $\mathrm{pCR}$ in NAC with trastuzumab has not yet been ascertained. Previous studies suggested that breast cancers over-expressing HER2 become resistant to trastuzumab by activating the PI3K/Akt signaling pathway and downregulating p27 ${ }^{\text {Kip1 }}[27,28]$. Activated Akt phosphorylates $\mathrm{p} 27^{\mathrm{Kip} 1}$, which may result in the mislocation of $\mathrm{p} 27^{\mathrm{Kip} 1}$ to the cytoplasm, in which it is unable to inhibit cell cycle proteins; nuclear localization is important for its cell cycle inhibitory function [29]. Low amounts of $\mathrm{p} 27^{\mathrm{Kip} 1}$ in the nucleus and resultant activation of cyclin-dependent kinases in the nucleus may increase the proliferation of tumor cells [30,31]. Difficulties are associated with evaluating the expression of $\mathrm{p} 27^{\mathrm{Kip} 1}$ because 3 potential expression patterns exist: only in the nucleus, only in the cytoplasm, and in both the nucleus and cytoplasm [32, 33]. Stendahl et al. [34] previously defined grade 3 of $\mathrm{p} 27^{\mathrm{Kip} 1}$ as $75 \%$ or more cancer cells with p27 ${ }^{\text {Kip } 1}$-positive nuclei. By using the same cut-off (75\%) in the present study, we found that the weak expression of $\mathrm{p} 27^{\text {Kip1 }}$ was predictive of $\mathrm{pCR}$ (low, $71.0 \%$ vs. high, $50.0 \%)$.

The results of the present study indicated that a set of 5 factors (HG, ER, PgR, Ki67, and p2 $7^{\mathrm{Kip} 1}$ ) more accurately predicted $\mathrm{pCR}$ than each factor individually. $\mathrm{PCR}$ prediction scores of 0 to 5 , which were calculated based on the presence of a combination of these factors, predicted pCR rates of $0 \%$ to $84.3 \%$. Prospective studies are needed to determine whether $\mathrm{pCR}$ prediction scores accurately predict $\mathrm{pCR}$.

As reported in recent clinical trials on HER2-positive breast tumors [6, 35], pCR after NAC with HER2targeted agents may be a surrogate marker of prognosis; however, our results indicated that RFS was significantly better in patients with pCR after NAC with trastuzumab than in those with non-pCR. This result was consistent with previous findings reported by the NSABP B-18 [2] and B-27 [3] studies. In the NSABP B-27 trial, patients without nodal involvement had significantly better OS rates than those with nodal involvement if nodal involvement was the only parameter analyzed, and OS rates decreased as the number of involved nodes increased [2]. As noted above, recent studies suggest that $\mathrm{pCR}$ criteria include the lack of nodal involvement (e.g., "ypT0 ypNO" and "ypTis ypNo") [36]. In the present study, nodal involvement was significantly predictive of low OS rates in patients with pCR. Three out of the 5 patients with pCR and nodal involvement had recurrent tumors; 2 were HER2negative residual tumors in the axillary nodes. Differences in the expression of HER2 between primary breast tumors and metastatic tumors in regional nodes or at distant sites may reflect the heterogeneous characteristics of tumors.

HER2-positive tumors are ER-positive (designated luminal B-like, HER2-overexpressing) or ER-negative (designated non-luminal, HER2-enriched) [37]. In our study, pCR rates were significantly higher in patients with non-luminal-like tumors than in those with luminal-like tumors. Cross-talk between the ER and HER2 signaling pathways in luminallike tumors may be responsible for the lower response of these tumors to NAC with trastuzumab [38]. pCR was previously reported to be predictive of high survival rates in most patients with breast cancer, but not in patients with luminal-like tumors [22, 39]. However, as demonstrated in the present study, pCR was predictive of RFS rates, even in patients with luminal-like breast cancer if their tumors had a high Ki67 LI ( $\geq 30 \%$ ). Therefore, pCR in combination with a high Ki67 LI at baseline may be predictive of survival rates in patients with luminal-like, HER2-overexpressing breast cancer.

\section{Conclusions}

In the present study, we confirmed that NAC using taxanes followed by FEC concurrent with trastuzumab was a useful regimen for obtaining a high $\mathrm{pCR}$ rate of more than $65 \%$. By histopathological and immunohistochemical evaluations, we identified high HG, ER-negative, PgRnegative, high Ki67 LI, and low $\mathrm{p} 27^{\mathrm{Kip} 1}$ as significant predictive factors of $\mathrm{pCR}$. In addition, significantly better prognoses were achieved in the $\mathrm{PCR}$ group and pathologically negative lymph node group after this regimen of NAC with trastuzumab.

\section{Additional files}

Additional file 1: Patient and tumor characteristics at baseline. (PDF 6 kb) 
Additional file 2: Results of the multivariate analysis of clinicopathological factors influencing the prediction of $\mathrm{pCR}$. (PDF $47 \mathrm{~kb}$ )

Additional file 3: $\mathrm{pCR}$ prediction scores and their relationship with pCR (odds ratio and $95 \%$ confidence intervals). (PDF $17 \mathrm{~kb}$ )

\section{Abbreviations}

NAC: neoadjuvant chemotherapy; HER2: human epidermal growth factor receptor 2; FEC: fluorouracil, epirubicin and cyclophosphamide; pCR: pathological complete response; RFS: relapse-free survival; OS: overall survival; LI: labeling index; JBCS: Japanese Breast Cancer Society; DCIS: noninvasive cancers; AJCC: American Joint Committee on Cancer Staging System; FISH: fluorescence in situ hybridization; PI3K: phosphatidylinositol 3-kinase; FDA: Food and Drug Administration; HR: hazard ratio.

\section{Competing interests}

IT received a donation from CHUGAI Pharmaceutical CO., LTD. in Japan. All remaining authors have declared no conflicts of interest.

\section{Author contributions}

All authors participated in the study design. SK mainly performed immunohistochemical evaluations, image acquisition, and statistical analyses, and drafted the manuscript. $\mathrm{KI}, \mathrm{HT}, \mathrm{HM}$, and MK assisted in production of the study design and evaluating the results. MK assisted SK in histological and immunohistochemical examinations and evaluating results. JH, IT, and TO contributed in statistical evaluation of results and theoretical organization of manuscript. All authors have read and approved the manuscript.

\section{Acknowledgments}

This study was presented in part at the 2012 Annual Meeting of the American Society of Clinical Oncology, Chicago, Illinois in June 2012.

A part of this work was supported by a grant from the Ministry of Health, Labour and Welfare of Japan.

\section{Author details}

${ }^{1}$ Division of Breast Surgery, Saitama Cancer Center, Saitama, Japan. ${ }^{2}$ Division of Breast Oncology, Saitama Cancer Center, Saitama, Japan. ${ }^{3}$ Department of Pathology, Saitama Cancer Center, 780 Komuro, Ina-machi, Kitaadachi-gun, Saitama 362-0806, Japan. ${ }^{4}$ Department of Thoracic and Visceral Organ Surgery, Gunma University Graduate School of Medicine, Maebashi, Gunma, Japan. ${ }^{5}$ Department of Diagnostic Pathology, Gunma University Graduate School of Medicine, Maebashi, Gunma, Japan.

\section{Received: 13 August 2014 Accepted: 1 September 2015}

Published online: 07 September 2015

\section{References}

1. Fisher B, Bryant J, Wolmark N, Mamounas E, Brown A, Fisher ER, et al. Effect of preoperative chemotherapy on the outcome of women with operable breast cancer. J Clin Oncol. 1998;16(8):2672-85.

2. Bear HD, Anderson S, Smith RE, Geyer Jr CE, Mamounas EP, Fisher B, et al. Sequential preoperative or postoperative docetaxel added to preoperative doxorubicin plus cyclophosphamide for operable breast cancer: National Surgical Adjuvant Breast and Bowel Project Protocol B-27. J Clin Oncol. 2006;24(13):2019-27.

3. Ross JS, Slodkowska EA, Symmans WF, Pusztai L, Ravdin PM, Hortobagyi GN. The HER-2 receptor and breast cancer: ten years of targeted anti-HER-2 therapy and personalized medicine. Oncologist. 2009;14(4):320-68.

4. Burstein HJ, Harris LN, Gelman R, Lester SC, Nunes RA, Kaelin CM, et al. Preoperative therapy with trastuzumab and paclitaxel followed by sequential adjuvant doxorubicin/cyclophosphamide for HER2 overexpressing stage II or III breast cancer: a pilot study. J Clin Oncol. 2003;21(1):46-53.

5. Gianni L, Pienkowski T, Im YH, Roman L, Tseng LM, Liu MC, et al. Efficacy and safety of neoadjuvant pertuzumab and trastuzumab in women with locally advanced, inflammatory, or early HER2-positive breast cancer (NeoSphere): a randomised multicentre, open-label, phase 2 trial. Lancet Oncol. 2012;13:25-32.

6. Baselga J, Bradbury I, Eidtmann H, Di Cosmo S, de Azambuja E, Aura C, et al. Lapatinib with trastuzumab for HER2-positive early breast cancer
(NeoALTTO): a randomised, open-label, multicentre, phase 3 trial. Lancet. 2012;379:633-40.

7. Limentani SA, Brufsky AM, Erban JK, Jahanzeb M, Lewis D. Phase II study of neoadjuvant docetaxel, vinorelbine, and trastuzumab followed by surgery and adjuvant doxorubicin plus cyclophosphamide in women with human epidermal growth factor receptor 2-overexpressing locally advanced breast cancer. J Clin Oncol. 2007;25(10):1232-8.

8. Buzdar AU, Ibrahim NK, Francis D, Booser DJ, Thomas ES, Theriault RL, et al. Significantly higher pathologic complete remission rate after neoadjuvant therapy with trastuzumab, paclitaxel, and epirubicin chemotherapy: results of a randomized trial in human epidermal growth factor receptor 2-positive operable breast cancer. J Clin Oncol. 2005;23:3676-85.

9. Zaczek A, Brandt B, Bielawski KP. The diverse signaling network of EGFR, HER2, HER3 and HER4 tyrosine kinase receptors and the consequences for therapeutic approaches. Histol Histopathol. 2005;20(3):1005-15.

10. Lane HA, Beuvink I, Motoyama AB, Daly JM, Neve RM, Hynes NE. ErbB2 potentiates breast tumor proliferation through modulation of p27 $\left({ }^{K i p 1}\right)-C d k 2$ complex formation: receptor overexpression does not determine growth dependency. Mol Cell Biol. 2000;20(9):3210-23.

11. Lewis GD, Figari I, Fredly B, Wong WL, Carter P, Gorman C, et al. Differential responses of human tumor cell lines to anti-p185HER2 monoclonal antibodies. Cancer Immunol Immunother. 1993;37(4):255-63.

12. Sliwkowski MX, Schaefer G, Akita RW, Lofgren JA, Fitzpatrick VD, Nuijens A, et al. Coexpression of erbB2 and erbB3 proteins reconstitutes a high affinity receptor for heregulin. J Biol Chem. 1994;269(20):14661-5.

13. Hurvitz SA, Betting DJ, Stern HM, Quinaux E, Stinson J, Seshagiri S, et al. Analysis of Fcgamma receptor IIla and Ila polymorphisms: lack of correlation with outcome in trastuzumab-treated breast cancer patients. Clin Cancer Res. 2012;18(12):3478-86.

14. Sliwkowski MX, Mellman I. Antibody therapeutics in cancer. Science. 2013;341(6151):1192-8

15. Pietras RJ, Fendly BM, Chazin VR, Pegram MD, Howell SB, Slamon DJ. Antibody to HER-2/neu receptor blocks DNA repair after cisplatin in human breast and ovarian cancer cells. Oncogene. 1994;9(7):1829-38.

16. Pegram M, Hsu S, Lewis G, Pietras R, Beryt M, Sliwkowski M, et al. Inhibitory effects of combinations of HER-2/neu antibody and chemotherapeutic agents used for treatment of human breast cancers. Oncogene. 1999;18(13):2241-51.

17. Konecny G, Fritz M, Untch M, Lebeau A, Felber M, Lude S, et al. HER-2/neu overexpression and in vitro chemosensitivity to CMF and FEC in primary breast cancer. Breast Cancer Res Treat. 2001;69(1):53-63.

18. Seidman AD, Fornier MN, Esteva FJ, Tan L, Kaptain S, Bach A, et al. Weekly trastuzumab and paclitaxel therapy for metastatic breast cancer with analysis of efficacy by HER2 immunophenotype and gene amplification. J Clin Oncol. 2001;19(10):2587-95.

19. Smith I, Procter M, Gelber RD, Guillaume S, Feyereislova A, Dowsett M, et al. 2-year follow-up of trastuzumab after adjuvant chemotherapy in HER2-positive breast cancer: a randomised controlled trial. Lancet. 2007;369(9555):29-36.

20. Buzdar AU, Valero V, Ibrahim NK, Francis D, Broglio KR, Theriault RL, et al. Neoadjuvant therapy with paclitaxel followed by 5 -fluorouracil, epirubicin, and cyclophosphamide chemotherapy and concurrent trastuzumab in human epidermal growth factor receptor 2-positive operable breast cancer: an update of the initial randomized study population and data of additional patients treated with the same regimen. Clin Cancer Res. 2007:13:228-33.

21. Untch M, Fasching PA, Konecny GE, Hasmuller S, Lebeau A, Kreienberg R, et al. Pathologic complete response after neoadjuvant chemotherapy plus trastuzumab predicts favorable survival in human epidermal growth factor receptor 2-overexpressing breast cancer: results from the TECHNO trial of the AGO and GBG study groups. J Clin Oncol. 2011;29(25):3351-7.

22. von Minckwitz G, Untch M, Blohmer JU, Costa SD, Eidtmann H, Fasching PA, et al. Definition and impact of pathological complete response on prognosis after neoadjuvant chemotherapy in various intrinsic breast cancer subtypes. J Clin Oncol. 2012;30:1796-804.

23. Polyak K, Lee MH, Erdjument-Bromage H, Koff A, Roberts JM, Tempst P, et al. Cloning of p27Kip1, a cyclin-dependent kinase inhibitor and a potential mediator of extracellular antimitogenic signals. Cell. 1994;78(1):59-66.

24. Toyoshima H, Hunter T. p27, a novel inhibitor of G1 cyclin-Cdk protein kinase activity, is related to p21. Cell. 1994;78(1):67-74.

25. Tanaka T, Tatsuno I, Noguchi Y, Uchida D, Oeda T, Narumiya S, et al. Activation of cyclin-dependent kinase $2(\mathrm{Cdk} 2)$ in growth-stimulated rat 
astrocytes. Geranylgeranylated Rho small GTPase(s) are essential for the induction of cyclin E gene expression. J Biol Chem. 1998;273(41):26772-8.

26. Koff A, Giordano A, Desai D, Yamashita K, Harper JW, Elledge S, et al. Formation and activation of a cyclin E-cdk2 complex during the G1 phase of the human cell cycle. Science. 1992;257(5077):1689-94.

27. Nahta R, Takahashi T, Ueno NT, Hung MC, Esteva FJ. P27 (kip1) downregulation is associated with trastuzumab resistance in breast cancer cells. Cancer Res. 2004;64:3981-6.

28. Mukohara T. Mechanisms of resistance to anti-human epidermal growth factor receptor 2 agents in breast cancer. Cancer Sci. 2011;102:1-8.

29. Shin I, Yakes FM, Rojo F, Shin NY, Bakin AV, Baselga J, et al. PKB/Akt mediates cell-cycle progression by phosphorylation of p27(Kip1) at threonine 157 and modulation of its cellular localization. Nat Med. 2002:8(10):1145-52.

30. Cariou S, Catzavelos C, Slingerland JM. Prognostic implications of expression of the cell cycle inhibitor protein p27Kip1. Breast Cancer Res Treat. 1998;52 (1-3):29-41.

31. Catzavelos C, Bhattacharya N, Ung YC, Wilson JA, Roncari L, Sandhu C, et al. Decreased levels of the cell-cycle inhibitor p27Kip1 protein: prognostic implications in primary breast cancer. Nat Med. 1997;3(2):227-30.

32. Barnes A, Pinder SE, Bell JA, Paish EC, Wencyk PM, Robertson JFR, et al. Expression of p27kip1 in breast cancer and its prognostic significance. J Pathol. 2003:201:451-9.

33. Singh SP, Lipman J, Goldman H, Ellis Jr FH, Aizenman L, Cangi MG, et al. Loss or altered subcellular localization of p27 in Barrett's associated adenocarcinoma. Cancer Res. 1998;58(8):1730-5.

34. Stendahl M, Nilsson S, Wigerup C, Jirstrom K, Jonsson PE, Stal O, et al. p27Kip1 is a predictive factor for tamoxifen treatment response but not a prognostic marker in premenopausal breast cancer patients. Int J Cancer. 2010;127:2851-8.

35. Piccart-Gebhart MJ, Holmes AP, Baselga J, Azambuja ED, Dueck AC, Viale G, et al. First results from the phase III ALTTO trial (BIG 2-06; NCCTG [Alliance] N063D) comparing one year of anti-HER2 therapy with lapatinib alone $(\mathrm{L})$, trastuzumab alone $(T)$, their sequence $(T \rightarrow L)$, or their combination $(T+L)$ in the adjuvant treatment of HER2-positive early breast cancer (EBC). J Clin Oncol. 2014;32:5s

36. Cortazar P, Zhang L, Untch M, Mehta K, Costantino JP, Wolmark N, et al. Pathological complete response and long-term clinical benefit in breast cancer: the CTNeoBC pooled analysis. Lancet 2014, Feb 13 [Epub ahead of print] doi: 10.1016

37. Perou CM, Sorlie T, Eisen MB, van de Rijn M, Jeffrey SS, Rees CA, et al. Molecular portraits of human breast tumours. Nature. 2000;406(6797):747-52.

38. Bhargava R, Beriwal S, Dabbs DJ, Ozbek U, Soran A, Johnson RR, et al. Immunohistochemical surrogate markers of breast cancer molecular classes predicts response to neoadjuvant chemotherapy: a single institutional experience with 359 cases. Cancer. 2010;116(6):1431-9.

39. von Minckwitz G. Neoadjuvant chemotherapy in breast cancer - insights from the German experience. Breast Cancer. 2012;19:282-8.

\section{Submit your next manuscript to BioMed Central and take full advantage of:}

- Convenient online submission

- Thorough peer review

- No space constraints or color figure charges

- Immediate publication on acceptance

- Inclusion in PubMed, CAS, Scopus and Google Scholar

- Research which is freely available for redistribution

Submit your manuscript at www.biomedcentral.com/submit 